clinical situations by skilled nursing care. Assisted feeding by a nasogastric tube or gastrostomy tube is comparable to the use of urinary catheters in that once in place all these tubes are merely passive conduits that require little more than ordinary care and caution.

Moreover, when nutrition and fluids are denied to a patient that patient dies. When medical treatments are abated patients often continue to live-somewhat to the surprise of their physicians.

Clinical practice permits exceptions to such tubal procedures. They may be summarised in two categories: when providing assisted feeding is clinically impossible and when its mode of provision would itself cause radical and extreme pain to the patient.

Guild of Catholic Doctors,

London NW8 9NH

1 Dyer C. BMA examines persistent vegetative state. $B M \mathcal{Y}$ 1992;305:853-4. (10 October.)

\section{Radioiodine for hyperthyroidism}

EDrToR,-Jayne Franklyn and Michael Sheppard may have overstated the case for radioiodine for hyperthyroidism.' It is not entirely true that in Europe, the United States, and Japan thyrotoxicosis is now rarely considered to be an indication for partial thyroidectomy. Indeed, attention has recently been focused on more frequent use of surgical treatment because of its predictable outcome. $^{2}$ Some surgeons never see hypoparathyroidism or recurrent laryngeal nerve damage after surgery for Graves' disease, and the complication of recurrent hyperthyroidism should be much less than the $10 \%$ quoted by Franklyn and Sheppard. ${ }^{34}$ I agree that the incidence of hypothyroidism may well be $40 \%$ after surgery, but after adequate treatment with radioactive iodine the incidence of hypothyroidism may be $60 \%$ at one year and $90 \%$ at five years. ${ }^{5}$

In discussions of the role of radioactive iodine in hyperthyroidism the indication must be clearly identified because multinodular goitre is relatively unresponsive to this treatment and the pressure symptoms and cosmetic features of a large goitre are unlikely to be improved.

I agree with the authors that the risk of carcinogenesis is probably small; although it is true that radioactive iodine has been given in the United States for over 50 years, careful follow up studies have been of much shorter duration. The much quoted study by Dobyns et al was of patients treated between 1946 and 1968 for a maximum of 22 years; the authors stated that a much longer follow up would be necessary to assess the potential risk of malignancy. ${ }^{\circ}$

To refer to radioiodine as the best treatment option for hyperthyroidism is probably an oversimplification. It is, however, an effective and easily administered treatment for selected patients with Graves' disease, particularly older patients and the small number who have recurrence after failed surgery.

Department of Surgery

Cardiff Royal Infirmary

Cardiff CF2 ISZ

1 Franklyn J, Sheppard M. Radioiodine for hyperthyroidism. $B M F$ 1992;305:727-8. (26 September.)

2 Harada T, Shimaoka K, Mimura T, Ito K. Current treatment of Graves' disease. Surg Clin N Am 1987;67:299-314.

3 Lennquist $S$, Jorsto E, Carlsson G. Long term follow up after surgical treatment for hyperthyroidism. Br f Surg 1991;78: 1143.

4 Andaker L, Johansson J, Smeds S, Lennquist S. Surgery for hyperthyroidism: hemithyroidectomy plus contralateral resection or bilateral resection? A prospective randomised study of post operative compli

5 Kendall-Taylor P, Keir MJ, Ross WM. Ablative radioiodine therapy for hyperthyroidism: long term follow up study. $B M$ 1984;289:361-3.

6 Dobyns BM, Sheline GE, Workman JB, Tompkins EA McConahey WM, Becker DV. Malignant and benign neoplasms of the thyroid in patients treated for hyperthyroidism: report of the co-operative thyrotoxicosis therapy follow up study. I Clin Endocrinol Metab 1974;38:976-8.

Authors' REPLY,-We share Malcolm $\mathrm{H}$ Wheeler's view that it is important to collect long term data on patients with a history of radioiodine treatment for thyrotoxicosis. We disagree, however, with his comments regarding the use of radioiodine in those with toxic multinodula goitre. Whether higher doses of radioiodine are required in multinodular goitre remains unclear: recommended dose regimens vary from large doses of $740-1850 \mathrm{MBq}^{12}$ to standard doses of less than $555 \mathrm{MBq}^{3+}$ and few patients are unresponsive to this treatment. In addition, pressure symptoms and cosmetic features are unusual in those with toxic multinodular goitre, and shrinkage of goitre after radioiodine treatment is well recognised. ${ }^{50}$

We believe that surgical treatment of hyperthyroidism by experienced operators remains a useful option in a small number of patients. Nevertheless, recent surveys of thyroid specialists in Europe (including the United Kingdom), North America, and Japan, have shown that less than 5\% of specialists consider that hyperthyroidism is an indication for partial thyroidectomy, even in young patients. ${ }^{7}$

J A FRANKLYN

Department of Medicine,

University of Birmingham,

Queen Elizabeth Hospital,

Birmingham B15 2TH

1 Miller JM, Block MA. The autonomous functioning thyroid nodule: therapeutic considerations. Arch Surg 1968;96:386-93.

2 Hamburger JI. Solitary autonomously functioning thyroid lesions. Diagnosis, clinical features and pathogenetic conlesions. Diagnosis, clinical features
siderations. Am 7 Med 1975;58:740-8.

3 Molnar GD, Wilbur RD, Lee RE, Woolner LB, Keating FR. On the hyperfunctioning solitary thyroid nodule. Mayo Clin Proc the hyperfunctionin.

$4 \mathrm{Ng}$ Tang Fui SC, Maisey MN. Standard dose 1311 therapy for hyperthyroidism caused by autonomously functioning thyroid nodules. Clin Endocrinol 1979;10:69-77.

5 Kay TWH, d'Emden MC, Andrews JT, Martin FIR. Treatment of non toxic multinodular goitre with radioactive iodine. $A m$ Med 1988;84:19-22

6 Hegedus L, Hansen BM, Kundsen N, Hansen JM. Reduction of size of thyroid with radioactive iodine in multinodula non-toxic goitre. $B M \mathcal{1}$ 1988;297:661-2

7 Wartofsky L, Clinoer D, Solomon B, Nagataki S, Lagasse R, Nagayama $Y$, et al. Differences and similarities in the diagnosis and treatment of Graves' disease in Europe, Japan and the United States. Thyroid 1991;1:129-35.

EDIToR,-We hope that Jayne Franklyn and Michael Sheppard's editorial outlining the efficacy and safety of radioiodine for hyperthyroidism will encourage use of this treatment option for thyrotoxicosis. ${ }^{1}$ We disagree, however, with their statement regarding the risk of infertility after the larger doses of radioactive iodine used in treating thyroid cancer.

We have reported on a 13 year old boy who developed azoospermia due to irreversible testicular germ cell damage after treatment with $12950 \mathrm{MBq}$ of iodine-131 for papillary thyroid carcinoma four years previously. ${ }^{2}$ Handlesman and Turtle have reported testicular damage in adult men after radioiodine for thyroid cancer. ${ }^{3}$ They found dose dependent spermatogenic damage, with raised gonadotrophin concentrations up to 42 months after radioiodine treatment, and concluded that clinically important effects seemed to be restricted to men who received total doses exceeding $3700 \mathrm{MBq}$. Eighteen of 66 premenopausa women developed temporary ovarian failure during the first year after iodine-131 ablation treatment for thyroid carcinoma.

These studies suggest that large doses of radioactive iodine do cause gonadal failure in adults and children and that recovery from this damage may occur, at least in women. Detailed follow up studies of similarly treated patients are required to define the incidence of, and factors governing recovery from, this complication.

DOMHNALL O'HALLORAN STEPHEN M SHALET

Department of Medicine and Endocrinology,

Christie Hospital NHS Trust,

Manchester M20 9BX

1 Franklyn J, Sheppard M. Radioiodine for hyperthyroidism BMF 1992;305:727-8. (26 September.)

Ahmed SR, Shalet SM. Gonadal damage due to radioactive iodine (I131) treatment for thyroid carcinoma. Postgrad Med $\mathcal{f}$ 1985;61:361-2

3 Handlesman DJ, Turtle JR. Testicular damage after radioactive iodine (I-131) therapy for thyroid cancer. Clin Endocrinol 1983;18:465-72.

Raymond IP, Izembart M, Marliac V, Dagousset F, Merceron $\mathrm{RE}$, Valpillat $\mathrm{M}$, et al. Temporary ovarian failure in thyroid cancer patients after thyroid remnant ablation with radioactive iodine. F Clin Endocrinol Metab 1989;69:186-90.

\section{Diarrhoea during treatment with clozapine}

EDITOR,-R J Harvey and colleagues mention that "Because agranulocytosis occurs in 2-3\% of patients (with a mortality of up to $35 \%$ ), the drug can be dispensed only if regular blood count monitoring is performed by the pharmaceutical company." I believe that this is a misleading statement as I assume the $35 \%$ alluded to is the worldwide mortality of patients with agranulocytosis, including cases before routine monitoring was introduced. ${ }^{2}$

The current state of risk in the United Kingdom is that out of over 3000 patients who have received clozapine only one has died, and this death was not totally related to the agranulocytosis. This represents a risk rate of less than $0.03 \%$ in all clozapine patients in Britain, and given that $2-3 \%$ will have developed neutropenia then the risk even to them would be less than $0 \cdot 11 \%$

The accepted risk of agranulocytosis for conventional neuroleptic agents is $0 \cdot 1 \%$, and these drugs are unmonitored and often even unrecognised The suicide rate for chronic schizophrenia is $5 \%$, so it is probable that clozapine actually reduces mortality by more successfully dealing with the patient's negative symptoms.

I think that with monitoring clozapine is not only safe but also a valuable adjunct for the $20 \%$ of schizophrenic patients who are deemed untreatable, a statement with which the Committee on Safety of Medicines seems content.

Burnley BB11 2RF

MICHAEL LAUNER

1 Harvey RJ, Bullock T, Montgomery SA. Diarrhoea during reatment with clozapine: association with lymphocyte count. treatment with clozapine: associatio
$B M \mathcal{F}^{1}$ 1992;305:810. (3 October.)

2 Baldessarini RJ, Frankenburg FR Clozapine: a novel antipsychotic agent. N Engl f Med 1991;324:746-54.

3 Prudo R, Blum HM. Five year outcome and prognosis in schizophrenia. Brf Psychiatry 1987;150:345-54.

\section{Analgesia after surgery}

EDITOR,-Michael L Snaith recommends avoiding non-steroidal anti-inflammatory drugs perioperatively because of concerns regarding impaired wound healing but concedes that there is no strong evidence that this problem is of clinical importance. ${ }^{1}$ This advice may be intended in relation to chronic administration of non-steroidal antiinflammatory drugs in rheumatological and degenerative disorders, but if it is followed universally a much larger group of patients would be denied the benefits of these drugs. Snaith suggests that alternative analgesics, presumably opioids, be used in the perioperative period, 